\title{
Investigation of the Relationship between Public Green Space and Urban Life Quality
}

\author{
Raziyeh Teimouri (Corresponding author) \\ Geography and Urban Planning, Tabriz University, Tabriz, Iran \\ Tel: 98-914-913-9045Ｅ-mail: raziehteimouri@yahoo.com
}

\begin{abstract}
Rasoul Ghorbani
Professor in Geography and Urban Planning, Tabriz University, Tabriz, Iran
\end{abstract}

Tel: 98-914-913-9045Ｅ-mail: Ghorbani.rasoul@gmail.com

\begin{abstract}
Hamid Hodjati
Ph.d Candidate in Geography and Urban Planning, Tabriz University, Tabriz, Iran

Tel: 98-911-233-0916Ｅ-mail: hamid.hodjati@yahoo.com
\end{abstract}

Received: December 18, 2016 Accepted: January 15, 2017

doi:10.5296/emsd.v6i1.10467～URL: https://doi.org/10.5296/emsd.v6i1.10467

\begin{abstract}
Today, the green space development is on the considerable rise due to the population growth and increase of urban construction as well as the human needs for green space to achieve the social, physical and spiritual balance. The green space improves the environmental conditions of cities on one hand, and provides the citizens with leisure time on the other. The present study aims at investigating the socio-psychological effects of urban parks on the improvement of citizens' life quality via examining the factors encouraging the citizens of the Iranian city of Tabriz towards the urban parks. The findings of this research revealed that the citizens of Tabriz attend the aforesaid urban parks in order to access the clean air, family fun, pleasure, hiking and refreshment, and avoid any urban pollution and excessive small residential environment, as well as the recurring routine life.
\end{abstract}

Keywords: Urban park, Green space, Life quality, Tabriz 


\section{Introduction}

The aftermaths of urban development and the problems caused by the industrialization of metropolises have made significant protection of the factors effective on providing a convenient urban environment such as gardens and green spaces and improving socio-economic conditions, and as a result, development of the human society. The ecological development and balance between the nature and human being in urban scale goes based on the human and urban sustainable development (Yang, 2012). The urban green and open spaces are the natural survivors in cities which, on account of urban uncontrolled development, have been subject to qualitative and quantitative changes, bringing about many ecological, social and economic impacts (Jim, 2008). By increased demands of people to settle in urban lands, certain ecological and environmental roles turn to make the life quality convenient for human populations. Therefore, through urbanization processes, natural features such as the flora and untouched soil are replaced by construction materials in residential areas, commercial buildings, roads and parking lots (Thaiutsa, B., et al. 2008). Urban parks have been viewed as an important part of urban and community development more than just as setting for recreation (Konijnendijk, 2013).

Studies show that the built environment can both enable and limit physical activity participation (MacCormack ,2010).Having access to green space in cities, accordingly, is key to support the urban social and ecological systems (Barbosa and et al. 2007). In order to approve the different roles of the green space, a certain level of qualitative progress and green space distribution in urban areas should be considered which has been included in environmental sustainability agenda (Md \& Atiqul, 2011). It goes without saying that urban parks play socio-economic and ecological roles, and provide advantages like contribution to treat mental illnesses, provide a favorable environment for raising children, social integration, protect the comfort, and an indicator for social development (Balram \& Dragicevic, 2005). Thus, right planning of the urban parks leaves positive effects on the physical and mental health (Shiri, 2006). Scientists have found that green space could help people in terms of relaxation, rejuvenation and violence reduction. Further to socio-physiological advantages, the urban environment may provide the managers and citizens with economic benefits. For example, air purification by trees may lead to cut in pollution reduction costs. Moreover, the aesthetic, historical, and recreational values of urban parks cause increase in the attractions of cities, tourism value and income, as a result (Cheisura, 2004). The urban parks and green spaces are able to provide valuable recreational opportunities for those who live in cities. From among the other roles of the above parks and green spaces are the opportunities for sports, relaxation, and physical and mental health as a means of preventing social exclusion via public access to facilities, supporting communities through public places, settle social problems and providing peaceful places in city to improve the public mental health (Heydari Chianeh \& et al., 2014). Urban green space has great potential for promoting life quality that allows citizens to achieve health benefits (Zhang et al, 2015). Rapid growth of cities is the risk for sustainability of cities and the citizen's quality of life (Riffat, et al, 2016). This is while most of the studies have stressed on urban parks and green spaces as effective factors on promotion of social life quality. According to Barbosa, et al. (2007), green space is vital in 


\section{Macrothink}

supporting the urban social and ecological systems. Citizens have different viewpoints to urban green space; therefore, they understand it differently due to their different needs (Germann \& Seeland, 2004). The present study investigated the different standpoints of the citizens of Tabriz to effective factors encouraging them to the urban parks.

\section{Introduction to the Study Area}

The Iranian city of Tabriz is the most important population center and an immigration-friendly and industrial hub in Northwest of the country which welcomes immigrants. The city sees an increasing physical development and population growth constantly. Having been known from many years back as a city surrounded by gardens with an excellent weather, Tabriz is considered today as an industrial city with minimum urban green space and parks among the Iranian metropolises. This city has a population of 1494998 citizens based on the population and housing census of 2011.

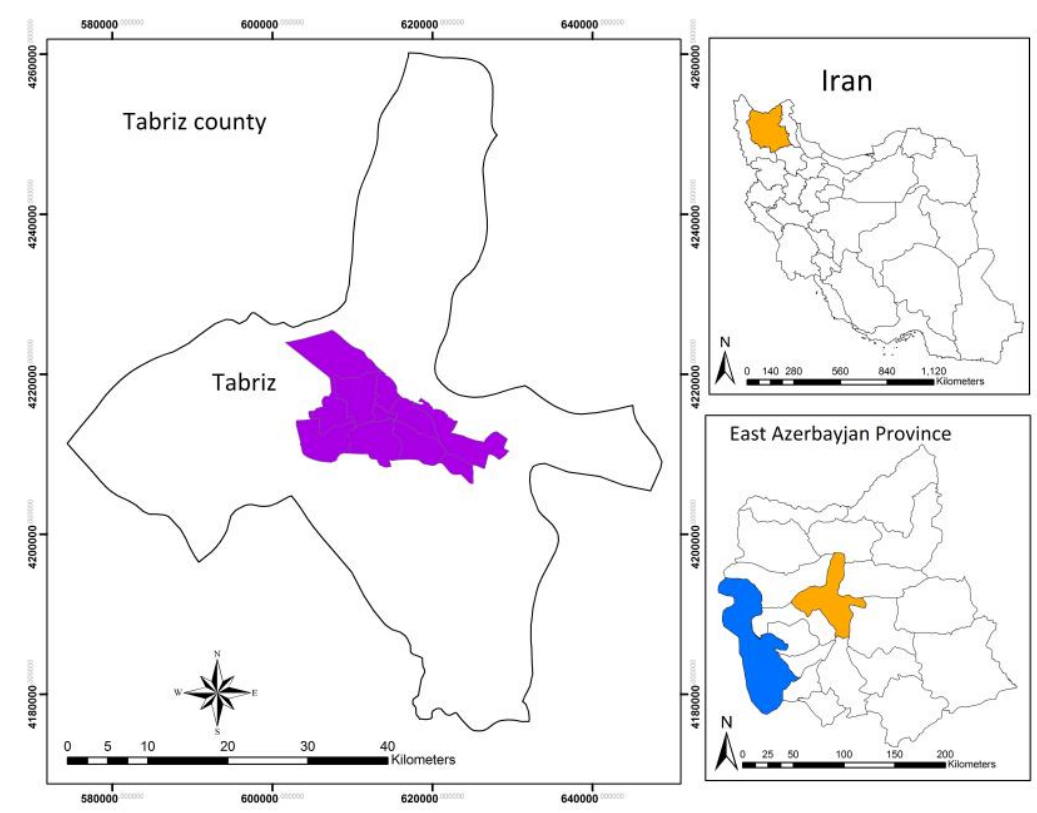

Figure 1. Study area

Examination of park and green space usage in the whole city indicated that the equipped parks, with social and recreational usage, in Tabriz is totally 6289175 square meters with 4.1 square meters per capita in the city. This is while its per capita criteria (based on the approvals of Iran's Supreme Council of Architecture and Urban Development) for a total of at least 9 meters in the whole city, representing a shortage of 4.9 square meters per individual. Factoring in the standard per capita, the total park space shortage in neighborhood, district and city is 751.5 hectares in the total Park and green space usage (Naghshe Mohit Consulting Engineers Co, 2015). 
Table 1. Park space shortage ratio to population and standard per capita in Tabriz

\begin{tabular}{|l|l|l|l|l|l|}
\hline $\begin{array}{l}\text { Population } \\
\text { census })\end{array}$ & $(2011$ & $\begin{array}{l}\text { Total area of parks in } \\
\text { Tabriz }\end{array}$ & $\begin{array}{l}\text { Current per } \\
\text { capita }\end{array}$ & $\begin{array}{l}\text { Standard per } \\
\text { capita }\end{array}$ & $\begin{array}{l}\text { Total park shortage in } \\
\text { city }\end{array}$ \\
\hline 1494998 & 6289175 & 4.20 & 9 & 7515325 \\
\hline
\end{tabular}

Source: Consulting Engineers of Naghshe Mohit Co, (2015). Physical studies of Tabriz master plan.

In the current research, four main urban parks of Tabriz, including the parks of Mashrouteh, Azarbaijan, El Gölü (or Elgoli), and Baghmisheh Forest which are located in the four corners of this city, were investigated.

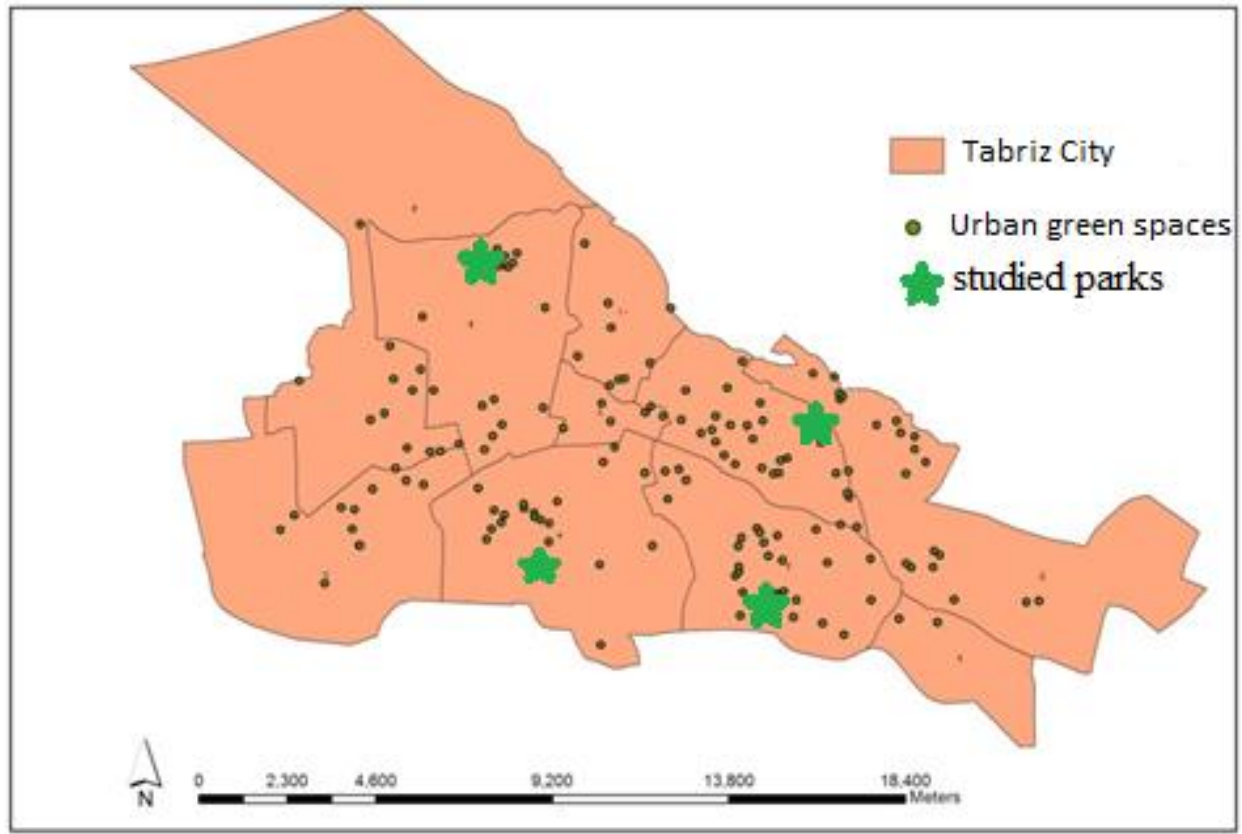

Figure 2. Dispersion of green spaces in Tabriz

With an area covering 610000 square meters, the El Gölü park is located in the district II of Tabriz. This park attracts visitors from Tabriz and even other cities because of its good weather and more natural attractions than other parks. Unlike El Gölü, Mashrouteh park is placed in the district III of Tabriz with an area of 140000 square meters. This park which is located next to the large bus terminal of Tabriz attracts only those citizens in its neighborhood. This park is built mostly with the purpose of welcoming the passengers and rehabilitation of deteriorated and outskirt areas within this district. The parks of Baghmisheh and Azarbaijan are located on both sides of the north highway of the city. These parks attract considerable number of visitors from distant areas. Azarbaijan park, placed in the district VI of Tabriz, is a part of the Great Park of Tabriz (covering 750000 square meters) and has not been used completely. Baghmisheh, however, is located in district V in northeast of Tabriz and covers 53000 square meters (Tabriz Parks \& Green Space Organization, 2015).

\section{Methodology}

Statistical population of this research included all citizens who visited four major city parks 


\section{MInstitute Macrothink}

of Tabriz. Random sampling was conducted. The data collection was carried out via a questionnaire in 100 citizens of Tabriz as visitors of the parks of Mashrouteh, Azarbaijan, El Gölü (or Elgoli), and Baghmisheh. The present study investigated the effective factors encouraging people to visit the parks via completing a number of questionnaires. In each park, 25 questionnaires were distributed among the visitors regardless of their social status or field of expertise. So, 100 questionnaires have been conducted. The aforesaid questionnaires were handed out on holidays and all days during a week at different times of the day and various places in the parks. The questions were a combination of multiple choice and open questions. The questionnaires were aimed at exploring reasons of people in visiting the parks, their related feelings, and escaping factors in their residing places, and examined the viewpoints of participants using the Likert scale.

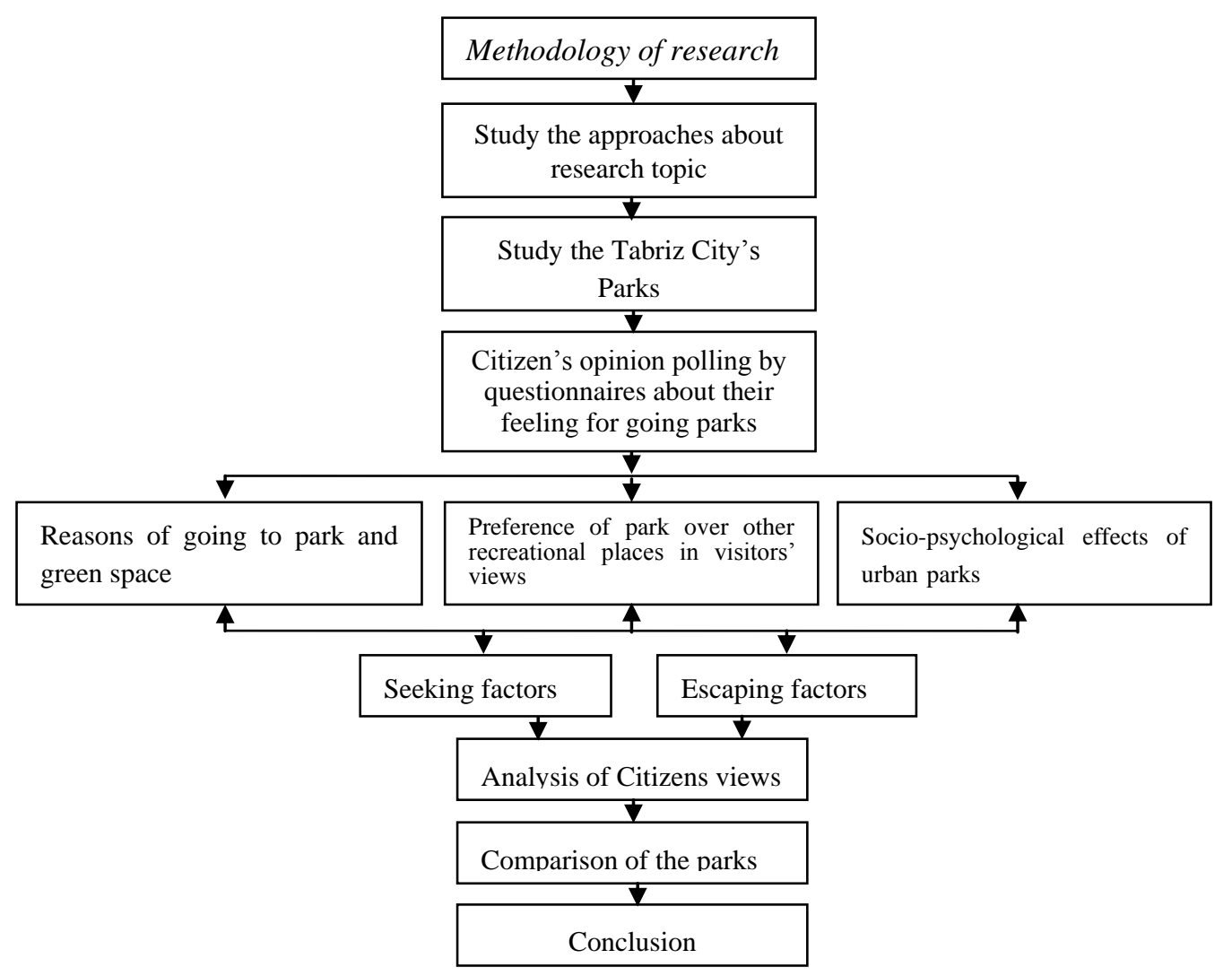

Figure 3. Flow Chart of Research Methodology

\section{Findings and Results}

Men and women accounted for $71 \%$ and $29 \%$ of the participants, respectively, in a survey conducted in the four main parks of Tabriz. The participants to this study were from 15 to 65 years of old, categorized in eight age groups out of which the most were 20-25 (27\%) and the next largest group comprised individuals of 25-30 (22\%). In terms of education, most of the contributors held diploma (31\%) and bachelor degrees (28\%). The respondents stated mostly that they go to the park once in several weeks. They believed evening as the best time of visiting parks, and summer and spring as the best seasons in this connection, respectively. $42 \%$ of the participants maintained that the best time duration to spend in parks, together with 


\section{Mll Macrothink}

Environmental Management and Sustainable Development

ISSN 2164-7682

2017, Vol. 6, No. 1

the family and friends, is 3 to 4 hours. The findings of this research were made up of four categories of reasons of going to park, repellents in living place, psychological effects on visitors, and preference of park over other recreational places.

\subsection{Reasons of Going to Park and Green Space}

Interest of people to natural areas and their different activities indicate their needs to such places and the needs they expect to be satisfied. The relevant information helps decision makers to present strategies which suit the public needs. The question of "State your reason for going to parks" was used in collecting the data on incentives of people in this connection.

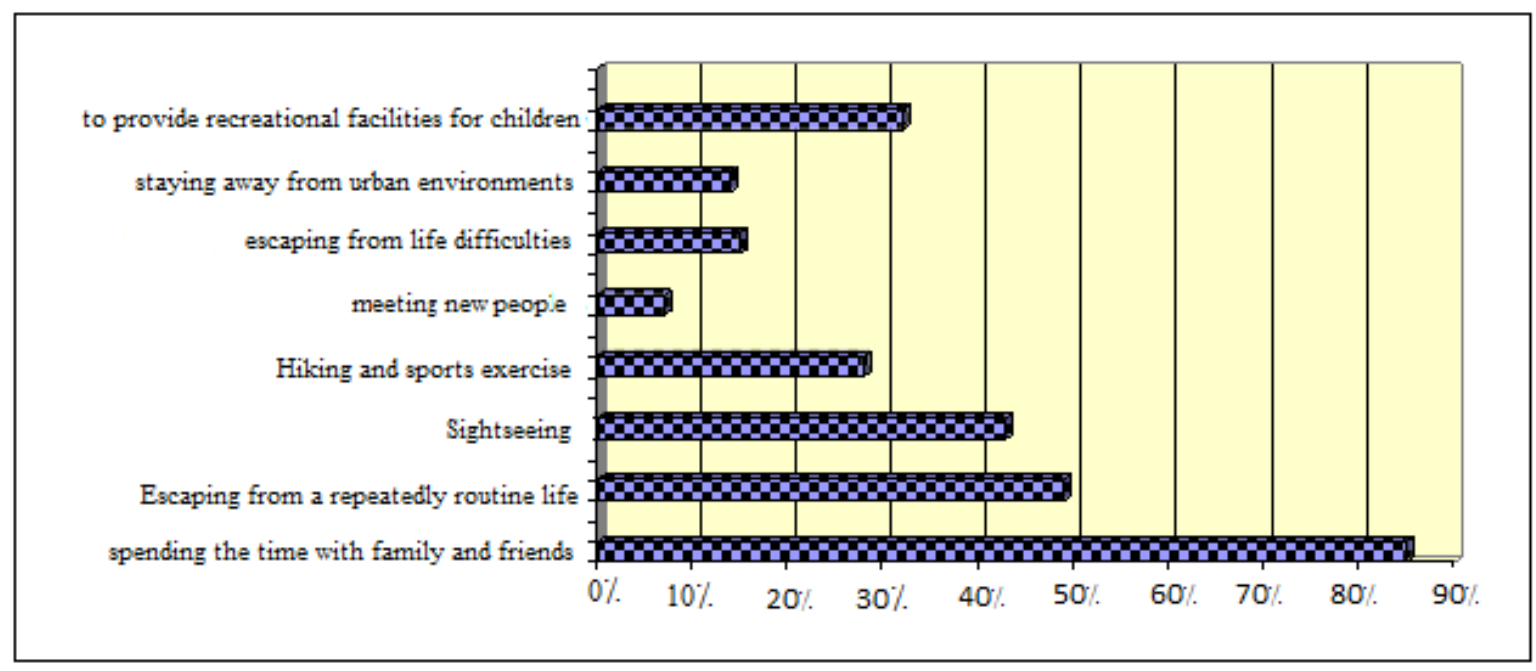

Figure 4.Main reasons of citizens for going the large parks in Tabriz

The frequency analysis of interests of people in nature demonstrated that spending the time with family and friends was the main reason of the most $(85 \%)$ of participants for visiting parks (figure 1). This is very normal because urban people obviously need interactions and being with others, free from family problems. Escaping from a repeatedly routine life was another important reason for the respondents (49\%), representing that people are not satisfied with this dimension of life and resort to parks to improve their life quality and diversity. Sightseeing is another incentive which was proposed in $43 \%$ of the responses. This shows human being is dependent on and in need of nature deeply. The findings indicate that $32 \%$ of participants go to such places to provide recreational facilities for children. This shows the important roles of nature in communities. Strengthening family ties and preparing a safe place for children, which is deemed as an urban gap in especially in modern cities, are included as social advantages of nature that is beneficial for both parents and children.

Hiking and sports exercise (28\%), escaping from life difficulties (15\%), staying away from urban environments (14\%), and meeting new people $(7 \%)$ were other reasons which demonstrates such social needs of citizens to resort to a quiet place distant from traffic and sound and other urban pollutions. The above notes are expected to be observed in green space planning in metropolises. 


\section{Macrothink}

Environmental Management and Sustainable Development

ISSN 2164-7682

2017, Vol. 6, No. 1

\subsection{Preference of Park over Other Recreational Places in Visitors'Views}

According to the completed questionnaires, $62 \%$ of the respondents believed access to fresh air as their main reason of going to parks, while $52 \%$ of the participants stated peaceful environment of parks as their preference reason in comparison with other recreational places. Proximity and easy access was a significant cause for $49 \%$ of the respondents to prefer to go to parks, and this indicates that those who live near the urban parks use these places easier to improve their life quality. Preference of parks over other similar places given that other recreational destinations are crowded and also using parks to do sports exercise were the next main reasons for selecting these places instead of other ones.

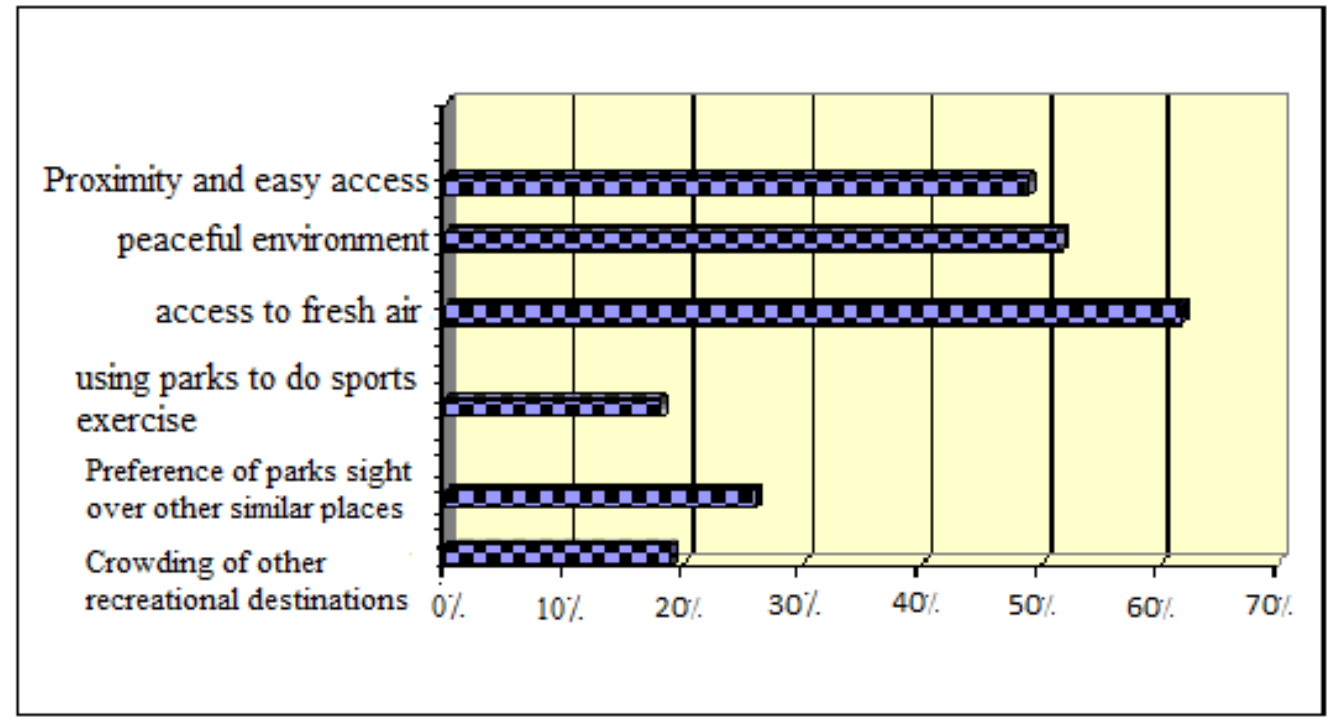

Figure 5. Reasons of preference of parks over other recreational places

\subsection{Socio-psychological Effects of Urban Parks}

The findings of the study revealed certain nature-based emotional dimensions and experiences representing a relationship between the advantages experienced by people and their general prosperity. In these connections, the participants were asked to answer to the question of "How do you feel when you are in park?"

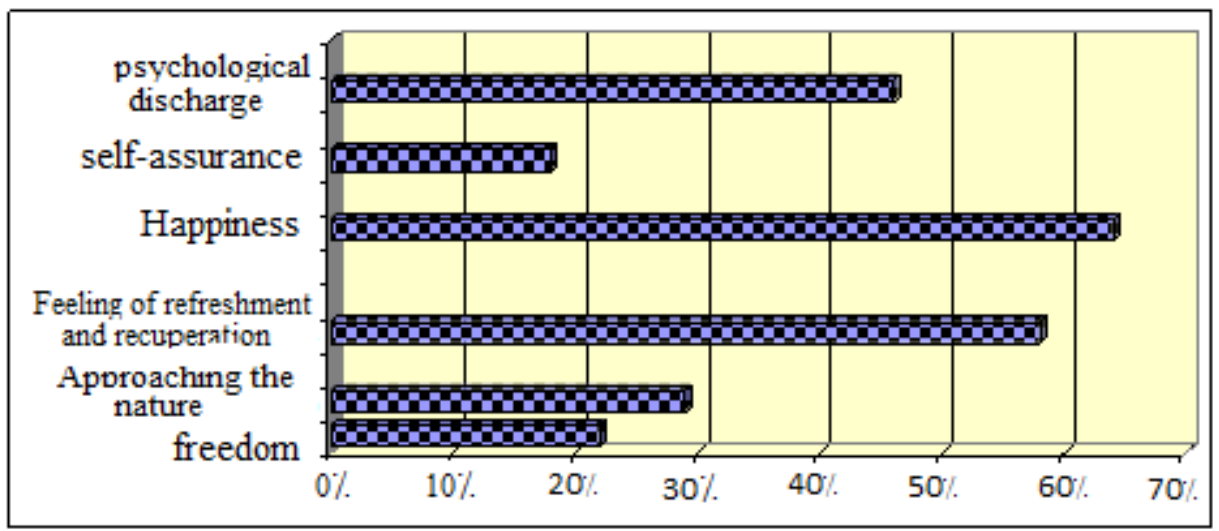

Figure 6. Experience feelings in the main parks in Tabriz 


\section{Macrothink}

Environmental Management and Sustainable Development

ISSN 2164-7682

2017, Vol. 6, No. 1

Happiness is a reason that was mentioned 64 times by participants and shows most of people feel happy and satisfied from being in parks. Feeling of refreshment and recuperation was seen in 58\% of the responses implying that following a business day, people go to parks to refresh and improve their life quality. The concept of psychological discharge with the frequency of $46 \%$ in responses introduces the park as a place to access peace of mind. Approaching the nature and freedom were included in $29 \%$ and $22 \%$ of the responses, respectively, while self-assurance was seen in the responses as a concept which was felt less than other aforesaid items by people in parks.

\subsection{Escaping Factors in Living Place}

As stated earlier, the present attempt was made to explore the reasons encouraging people to leave their houses and work places and head to parks. The participants to this study were asked to answer the question of "What are the factors encouraging you to leave your home in your free time?"

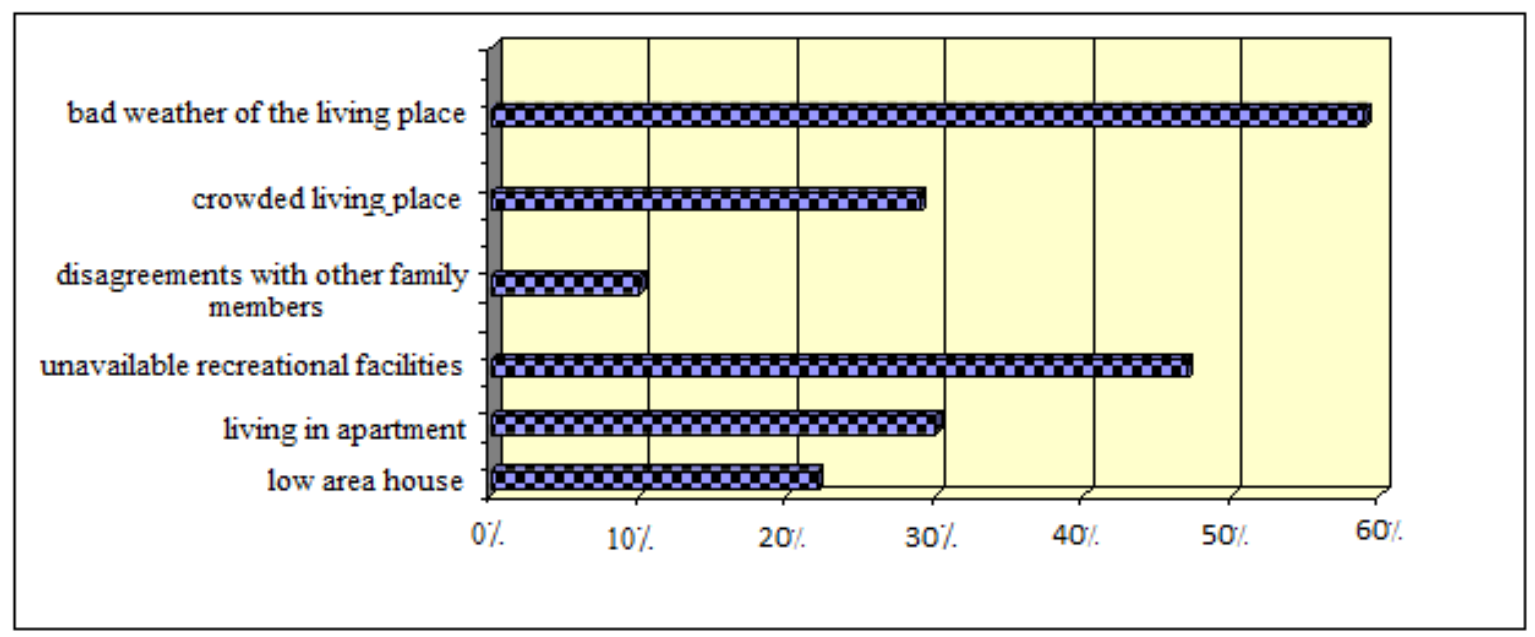

Figure 7. Escaping factors in living place (encouraging the citizens to go to the main

$$
\text { parks of Tabriz) }
$$

From among the proposed choices, the bad weather of the living place was found as the most important cause of leaving home for parks to enjoy the fresh air with the frequency of 59\% in responses. It is worth noting that the current survey was conducted in summer to cover more visitors in parks. $47 \%$ of the responses pointed out the unavailable recreational facilities at home as incentives to go to the urban parks in order to spend their leisure time using the beauty of the natural and artificial environments in parks. Urbanization and living in apartment is another escaping factor which appeared in $30 \%$ of the responses as a reason to motivate people to go to the parks. The crowded living place, low area house, and disagreements with other family members are found as the next escaping factors in this regard (figure 4).

\subsection{Analysis of Views on Seeking Factors of Urban Parks and Escaping Causes of Living Place Using Likert Scale}

Grading scales are the most common form of survey to assess complex issues or evaluate the 
differences between the stated opinions among which Likert scale is the most prevalent. Based on this scale, the respondents are asked to express their beliefs for or against a certain matter using a grading scale. The participants were asked in this study to show the extent of their agreement or disagreement on some comments. The for and against choices are used first to collect the attitudinal data. The responses are indicatives of values and this makes next step of analysis more flexible. This aims at evaluating the interests in a specific issue in line with social values. This investigates the approaches to socio-political and economic matters and is measured systematically (Hafeznia, 2005). Likert scale has five equal groups and the scholar provides the respondent with a number of items suitable for subject of the research so that $\mathrm{s} /$ he determines his/her attitude. The present study followed suit with seven questions from visitors of the urban parks. The participants responded to the questions in line with their opinions and attitudes of which the result is shown in figure 5.

a. Attending the park increases my occupational, educational and family-related efficiencies.

b. Attending the park promotes my life satisfaction.

c. Attending the park eases my peace of mind and getting through unpleasant thoughts.

d. Attending the park brings about physical and mental health and decreases illness.

e. Attending the park increases enjoying a collective life and being with others.

f. Staying at home in my free time makes me feel depressed.

g. Staying at home in my free time makes me feel trapped in a repeatedly routine life.

Based on the findings of this study, there is a relationship between the age of people and escaping from urban environments and seeking parks. The aforesaid findings unveiled also that younger people are more motivated to leave the urban uproar for nature and parks. Also, most of the attendants in parks felt happy of being there and prefer to spend their leisure time out of home in parks. They try to increase their occupational, educational and family efficiencies in the fresh air of the park and achieve prosperity, peace of mind, and collective life pleasure.

\subsection{Comparison of the Parks of El Gölü, Mashrouteh, Azarbaijan, and Baghmisheh}

Investigation of these four parks in Tabriz revealed that each possesses specific features. As the largest urban park in Tabriz, El Gölü goes beyond the city and region and is treated in certain dimensions at national level. Enjoying tourist capabilities, this park welcomes thousands of visitors from other cities every year. These indicate that unlike three other cities, El Gölü is the only park in which the factor of "easy access" does not play significant role for visitors. In this connection, only $9 \%$ of the respondents knew the aforementioned factor effective in visiting this park. On reasons of approaching the urban cities, the responses about the four studied parks were significantly different (figure 6).

In Baghmisheh park, citizens (52\%) expressed high cost cross-city travel as the main reason of using the urban parks. This is while in Mashrouteh park, 79\% of the participants believed nature driven mental peace as their main motivation of using urban parks. In Azarbaijan park, 
the most frequently mentioned cause encouraging people to attend this place was the good weather of the park and the mental peace as a result, whilst in El Gölü, the high cost of cross-city travels $(52 \%)$ and also the factor of family gathering make people leave their homes for the park. According to the completed questionnaires by the people attended the urban parks of Tabriz, literacy is a distinguishing factor between El Gölü and other Tabriz urban parks in a way that $68 \%$ of the participants to this study in El Gölü enjoyed higher education, compared to that of other abovementioned parks that was less than $20 \%$.

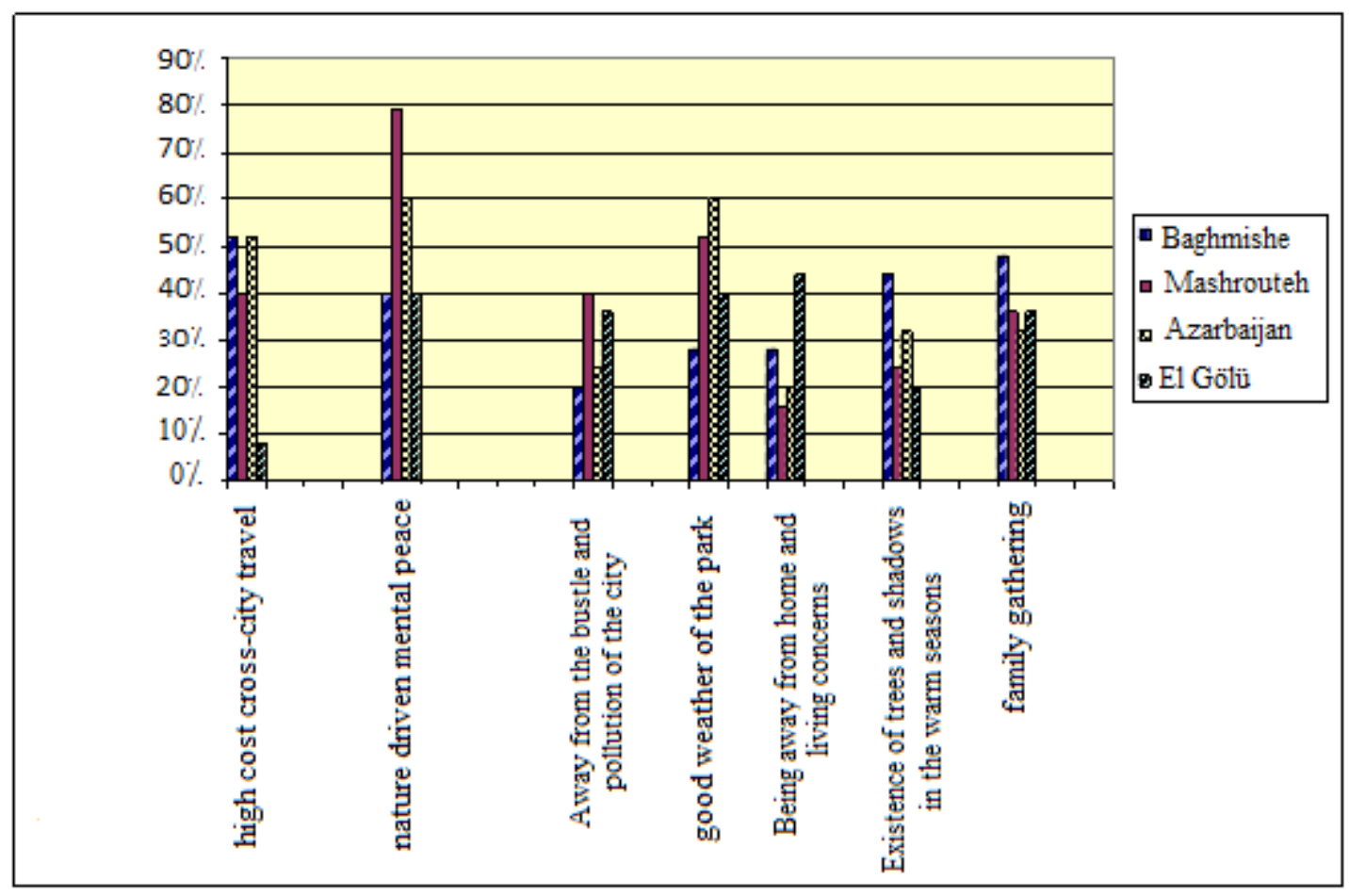

Figure 8. Reasons of attending the urban parks among the four main parks

\section{Conclusion}

All people of every social status and every age group pay attention to the important role of nature and its advantages in improving their mental and socio-economic conditions. Most of people feel happy of being in parks and see them a resort for refreshment in order to pursue their life, i.e. social, economic, etc. affairs, more actively. This shows that parks increase, directly or indirectly, the human life quality. Given the survey carried out in the four main urban parks of Tabriz and based on the questionnaires completed by the people attending these places on the escaping factors of living place and seeking causes of parks, the results revealed that most of people seek parks to spend their leisure time, enjoy collective life, be with others, avoid unpleasant weather, access recreational facilities, leave urbanism and escape from life difficulties. They, in other words, know being in parks an effective factor on reducing their depression, increasing their occupational and educational efficiencies, and keeping the recurring routine life at bay.

Taking the above mentioned findings and given the importance of parks for satisfying a part of mental and social needs of citizens, the development of the urban parks and green spaces 
together with the increasing development of Tabriz seems inevitable to improve the urban life quality. On the other hand, considering the fact that citizens of Tabriz spend two to five hours whenever they go to the large parks on passing their leisure time, the leisure enrichment must be seriously taken into consideration. The other important point is attending the parks with family members as a common behavior in Tabriz, and this has made this city in need of large parks with wide green space and amenities and various services for all family members. Also, given the significance of easy access to the urban parks, development of such places in different areas within the city would result in more attendance of people in parks and consequently, promote the life quality more and more in future.

\section{References}

Balram, Sh, \& Dragicevic, S. (2005). Attitudes Toward urban green Space: integrating questionnaire survey and collaborative GIS techniques to improve attitude measurements. Landscape and Urban planning 71, 149. http://dx.doi.org/10.1016/j.landurbplan.2004.02.007

Barbosa, O., et al., ( 2007). Who benefits from access to green space? A case study from Sheffield, Landscape and Urban Planning Journal. 83(2-3), 197-195.

http://dx.doi.org/10.1016/j.landurbplan.2007.04.004

Chiesura, A. (2004). The role of urban parks for the sustainable city. Landscape and urban planning, 68, 129-138. http://dx.doi.org/10.1016/j.landurbplan.2003.08.003

Consulting engineers of Naghshe Mohit, master plan studies about Tabriz. (2014).

General Population and Housing Census, Statistical Center of Iran, (2011).

Germann, C., \& Klaus, S. (2004). Are urban green space optimally distributed to act as place for social integration? Forest Policy and Economics, 6, 3-13.

http://dx.doi.org/10.1016/S1389-9341(02)00067-9

Hafeznia, MR. (2007). Introduction to Research Methods in Human Sciences. Samt publication.

Heydari Ch, R., \& et al., (2014), Measuring the success of women's only parks from the perspective of citizens, Case study; Tabriz Metropolis, Journal of Urban and Regional Studies and Research, fifth year, No 20.

Jim, C. Y., \& Chen, W. Y. (2008). Pattern and divergence of tree communities in Taipei's main urban green spaces, Journal of Landscape and Urban Planning, 84, 312-323. http://dx.doi.org/10.1016/j.landurbplan.2007.09.001

Konijnendijk, Cecil ,C., \&et al., (2013). Benefits of Urban Parks a systematic review. A report for IFPRA, Copenhagen \& Alnarp.

McCormack, G. R., \& et al. (2010). Characteristics of urban parks associated with parks use and physical activity: A review of qualitative research, Journal of Health and Place, 16, 712-726. http://dx.doi.org/10.1016/j.healthplace.2010.03.003

Md, Sh, \& Atiqul, H. (2011). Urban Green Spaces and an Integrative Approach to Sustainable 


\section{Macrothink \\ Environmental Management and Sustainable Development \\ ISSN 2164-7682 \\ 2017, Vol. 6, No. 1}

Environment. Journal of Environmental Protection, 2, 601-608.

http://dx.doi.org/10.4236/jep.2011.25069

Organization of parks and green space of Tabriz. statistics and information about Tabriz green spaces. (2015).

Shiri, A. (2006). Providing optimal spatial pattern for the urban green space in the city of Zanjan. using GIS. M.A thesis. University of Zanjan. Iran.

Thaiutsa, B \& et al. (2008). Urban green space, street tree and heritage large Tree assessment in Bangkok, Thailand. Urban Foresty and Urban Greening, 7(3), 219-229.

http://dx.doi.org/10.1016/j.ufug.2008.03.002

Yang ,Z. (2012). Eco-Cities, A Planning Guide. CRC Press, 12.

Zhang, W., \& et al., (2015). Factors affecting the use of urban green spaces for physical activities: Views of young urban residents in Beijing. Journal of Urban Foresty \& Urban Greening, 14, 851-857. http://dx.doi.org/10.1016/j.ufug.2015.08.006

Riffat, S., \& et al., (2016). Future Cities and Environmental Sustainability, Journal of Future Cities \& Environment, 2(1), 1-23. http://dx.doi.org/10.1186/s40984-016-0014-2

\section{Copyright Disclaimer}

Copyright for this article is retained by the author(s), with first publication rights granted to the journal.

This is an open-access article distributed under the terms and conditions of the Creative Commons Attribution license (http://creativecommons.org/licenses/by/3.0/). 